\title{
Early detection of airway obstruction by impulse oscillometry system in methacholine challenge testing in preschool children
}

\author{
Jung Won Yoon, ${ }^{1}$ Youn Ho Sheen, ${ }^{2}$ Eun Kyo Ha, ${ }^{3}$ Ji Hyun Baek, ${ }^{3}$ Hey Sung Baek, ${ }^{4}$ Sun Hee Choi, ${ }^{5}$ Man Yong Han ${ }^{1}$
}

\begin{abstract}
Background: Small airway hyperresponsiveness is a critical aspect in preschool children with asthmatic symptoms in terms of asthma control. The aim of this study was to elucidate the relationship of changes in reactance (Xrs) and resistance (Rrs) of IOS and FEV , with those in clinical parameters and to determine which IOS parameter is correlated with bronchial hyperresponsiveness before positive clinical endpoints.
\end{abstract}

Methods: We performed the methacholine challenge test in ninety-four preschool children $(4.2 \pm 1.1$ years $)$ with suspected asthma. The end of test $\left(\mathrm{EOT}^{+}\right)$was defined as one or more of the following: audible wheezing $\left(\mathrm{PCw}^{+}\right)$, a fall in the oxygen saturation $\left(<92 \%, \mathrm{PCs}^{+}\right)$or development of respiratory symptoms $\left(\mathrm{PCr}^{+}\right)$.

Results: Mean changes in $\mathrm{FEV}_{1}, \mathrm{Xrs}_{5}$, and $\mathrm{Rrs}_{5}$ in the $\mathrm{EOT}^{+}$group were $39.2 \pm 14.3 \%$ (95\% CI 35.1-43.2\%), 176.8 \pm 78.0 (95\% CI 154.9-198.8) and 53.6 \pm 30.2 (45.1-62.0), respectively. The changes of $\mathrm{Xrs}_{5}$ in three $\mathrm{EOT}^{+}$groups exceeded $80 \%$ and were lowest in $\mathrm{PCr}^{+}$(median, 95.9, IQR;73.4 to 132.4), followed by $\mathrm{PCw}^{+}$and $\mathrm{PCs}^{+}$. However, $\mathrm{Rrs}_{5}$ did not show greater than $40 \%$ changes in $\mathrm{PCr}^{+}$. $\mathrm{Xrs}_{5}$ showed a higher correlation with changes in saturation ( $\left.\mathrm{r}=-0.578\right)$ than $\mathrm{Rrs}_{5}(\mathrm{r}=-0.426)$. A49\% decrease in $\mathrm{Xrs}_{5}$ was the optimal point for predicting a $80 \%$ change of $\mathrm{Xrs}_{5}$ at the following step.

Conclusion: When examining the 5 step methacholine challenge test in preschoolers, the use of clinical parameters alone as an endpoint is of little value. The reactance value of $5 \mathrm{~Hz}$ is a useful predictive marker for bronchial hyperresponsiveness.

Keywords: Impulse Oscillation, Dose-response Slope, Bronchial hyperresponsiveness, Spirometry, auscultation method

\section{From:}

Department of Pediatrics, Myongji Hospital, Seonam University College of Medicine, Goyang, Republic of Korea

Department of Pediatrics, CHA Gangnam Medical Center, CHA University School of Medicine, Seoul, Republic of Korea

Department of Pediatrics, CHA Bundang Medical Center, CHA

University School of Medicine, Seongnam, Republic of Korea

${ }^{4}$ Department of Pediatrics, Kangdong Sacred Heart Hospital, Hallym

University, Seoul, Republic of Korea

Department of Pediatrics, Kyung Hee University School of Medicine, Seoul, Republic of Korea

\section{Background}

Measurements of bronchial hyperresponsiveness (BHR) have provided integral information for the diagnosis and management of lung diseases in children and adults. ${ }^{1}$ Forced spirometry can be feasible in preschool children, allowing evaluations of bronchodilator response $\mathrm{e}^{2}$ and baseline lung function. However, young children lack the ability to tolerate the repetitive measurements of bronchial challenge testing with spirometry and thus hindering its clinical use., Therefore, other methods have been used clinically to assess bronchial hyperresponsiveness in preschool children,

\section{Corresponding author:}

Man Yong Han

Department of Pediatrics

CHA University School of Medicine

351 Yatap-dong, Bundang-gu, Seongnam, Gyeonggi-do, 463-712,

Republic of Korea

E-mail: drmesh@gmail.com

including the auscultation method, ${ }^{4}$ transcutaneous oximetry, ${ }^{5}$ and transcutaneous oxygen tension, ${ }^{6}$ as well as other techniques to measure lung function, such as the forced oscillation technique (FOT), ${ }^{7}$ the impulse oscillation system (IOS), ${ }^{8}$ the interrupter technique, ${ }^{9}$ and plethysmography. ${ }^{10}$ However, these techniques have some limitations. Wheezing and cutaneous monitoring could be potentially dangerous to subjects, ${ }^{6}$ and interrupter technique is less sensitive in determining airway caliber in asthmatic children who undergo methacholine challenge testing. ${ }^{11}$ Body plethysmography and spirometry 
have lower success rates, ${ }^{12}$ and the equipment required for plethysmography limits its usefulness in clinical settings. ${ }^{13}$

Accordingly, studies using the oscillation technique to assess bronchial hyperresponsiveness in preschool children are increasing. ${ }^{8,14,15}$ Clinical use of methacholine provocation testing with five sequential concentration is limited in young children due to difficulty of performing the challenge test correctly and the lack of criteria for positive test in differentiating the asthmatic children.

Therefore, the purpose of this study was to investigate the relationship of changes in reactance and resistance of IOS and $\mathrm{FEV}_{1}$ with those in clinical endpoints such as oxygen saturation, auscultation and respiratory symptoms and to determine which IOS parameter is significantly correlated with bronchial hyperresponsiveness before positive clinical endpoints in preschoolers.

\section{Methods \\ Subjects}

We enrolled children with asthmatic symptoms such as recurrent wheezing episodes (more than twice) diagnosed at least once at the Pediatric Allergy clinic of CHA Bundang Medical Center who showed a positive bronchodilator response or improvement after taking inhaled corticosteroid between June 2010 and May 2012. The family and personal medical history of each subject were based on questionnaires, physical examinations, and lung function tests.

\section{Methacholine challenge testing}

Bronchial challenge testing was performed with 5-step quadrupling concentration doses $(0.0625,0.25,1,4$, and 16 $\mathrm{mg} / \mathrm{mL}$ methacholine dissolved in phosphate buffer). At each step, oxygen saturation, chest and tracheal auscultation, and subjective respiratory symptoms were checked by two experienced specialists and IOS pulmonary function tests were also performed. FEV, was measured by spirometry at baseline and at the end of the test due to concerns about exhaustion of the subject. IOS measurements were systematically taken prior to spirometry. The end point of a challenge for the EOT positive group $\left(\mathrm{EOT}^{+}\right)$was defined as one or more of the following: (a) audible wheeze over the chest or trachea (provocation concentration of wheezing; $\mathrm{PCW}^{+}$); (b) oxygen saturation below $91 \%$ (provocation concentration of saturation; $\mathrm{PCS}^{+}$); or (c) respiratory symptoms such as persistent cough, shortness of breath, or tachypnea for which the children were unable to sustain the test (provocation concentration of respiratory symptoms; $\left.\mathrm{PCr}^{+}\right) .{ }^{4,5}$ Subjects were defined as EOT negative $\left(\mathrm{EOT}^{-}\right)$if they reached a methacholine concentration of 16 $\mathrm{mg} / \mathrm{mL}$ without developing these manifestations. Each subject inhaledsolution for 1 minute using a nebulizer (DeVilbiss Health Care Inc., Somerset, PA) and a facemask, continuing every 5 minutes until the maximum concentration or end point was reached. ${ }^{4}$ All children were asked to abstain from bronchodilators for at least $12 \mathrm{~h}$ before methacholine challenge. After the methacholine challenge test, 4 puffs of salbutamol with a spacer were administered to the child. This study was approved by the Institutional Review Board of the CHA Bundang Medical Center, CHA University School of Medicine.
Written informed consent was obtained from the parents or guardians of all participants following a detailed explanation of the study.

\section{IOS}

IOS was performed 30,60 , and 90 seconds after methacholine inhalation in accordance with the ATS guidelines. For quality control, we monitored the visual acceptance of volume, flow and impedance traces. ${ }^{2}$ Participants breathed tidally into the IOS mouthpiece for at least 30seconds.

\section{Spirometry}

Spirometry was performed using a Jaeger MasterScreen device (Jaeger CO, Wurzburg, Germany), according the ATS guidelines. ${ }^{16}$ Spirometry results in these children were compared with those of healthy children by determining Z-scores. ${ }^{17}$

\section{Auscultation and saturation monitoring}

Auscultation was performed independently by an experienced pulmonary technician and a pediatrician (Han MY) at baseline and at each inhalationstep. ${ }^{18}$ The methacholine concentration at which wheezing was first heard clearly over the lung by both medical professionals was defined as the result of determination by auscultation $\left(\mathrm{PCW}^{+}\right)$. Oxygen saturation $\left(\mathrm{SpO}_{2}\right)$ was monitored using a finger oximeter $(\mathrm{GO} 2$, Nonin Medical Inc, Biox 3700e, Minnesota, USA). The percent reduction in oxygen saturation was calculated using the following formula: $100 \times$ (baseline saturation - post saturation)/ (baseline saturation). Changes in saturation were grouped as $<2 \%$ (S1), 2-3.9\% (S2), 4-5.9\% (S3), 6-7.9\% (S4) and $\geq 8 \%$ (S5). The mean percent reduction in oxygen saturation during bronchial challenge was approximately $3 \%$, included in the S2 group. ${ }^{19}$

\section{Calculation of cumulative dose of methacholine}

Methacholine chloride (Sigma Chemical, St. Louis, MO, USA) was inhaled usinga PARI BOY nebulizer (PARI GmbH, Starnberg, Germany), with a mean output of $0.20 \pm 0.02 \mathrm{ml} /$ $\mathrm{min}$. The dose response slope was defined as percent reduction in $\mathrm{FEV}_{1}$ from baseline to the final dose of methacholine administered divided by the final cumulative dose. ${ }^{20}$

Although bronchial hyperresponsiveness is usually confirmed by measuring $\mathrm{PC}_{20} \mathrm{FEV}_{1}$, the provocative concentration causing a $20 \%$ fall in $\mathrm{FEV}_{1}$ by spirometry, ${ }^{21}$ we were not able to calculate $\mathrm{PC}_{20} \mathrm{FEV}_{1}$ accurately as $\mathrm{FEV}_{1}$ was performed only at baseline and at the last step and described as dichotomy of positive or negative results. We therefore used the dose-response slope, ${ }^{22,23} \mathrm{PC}_{80} \mathrm{Xrs}_{5}{ }^{8,23,24}$ and $\mathrm{PC}_{40} \mathrm{Rrs}_{5}{ }^{14,25,26}$ to compare bronchial hyperresponsiveness in our $\mathrm{EOT}^{+}$and EOT ${ }^{-}$groups. $\mathrm{PC}_{80} \mathrm{Xrs}_{5}$ and $\mathrm{PC}_{40} \mathrm{Rrs}_{5}$ positive means that the rate of change in the last step from baseline decreased by $80 \%$ or more in reactance and increased by $40 \%$ or more in resistance when measuring with IOS. The method of calculating DRS is briefly described as follows. ${ }^{22,23}$ We obtained the cumulative dose at each level expressed in micromoles as $0.014,0.072,0.302,1.222$, and $4.901 \mathrm{mmol}$, respectively, which were obtained using the molecular weight of methacholine chloride $(195.7 \mathrm{~g} / \mathrm{mol})$. The slope was defined as log (percent 
change in $\mathrm{X}$ /last cumulative dose), where $\mathrm{X}$ represents $\operatorname{Rrs}_{5}$, $\mathrm{Xrs}_{5}$, and $\mathrm{FEV}_{1}$.

\section{Statistics}

Continuous variables in the $\mathrm{EOT}^{+}$and $\mathrm{EOT}^{-}$groups were compared using the independent Student's $t$ tests, and categorical variables were compared using the chi squared tests. Pearson correlation analysis was used to analyze changes in $\mathrm{SpO}_{2}, \mathrm{Xrs}_{5}$, and $\mathrm{Rrs}_{5}$. Analysis of variance testing with post hoc LSD analysis was used to assess differences among the S1 S5 groups.ROC curves were used to predict $80 \%$ changes in $\mathrm{Xrs}_{5}$ at each step. All statistical analyses were performed with PASW statistical software (version 20.0; PASW Statistics; Chicago, IL, USA). All statistical tests were two-sided and statistical significance was defined as a $P$ value $<0.05$.

\section{Results}

\section{Characteristics of subjects}

The anthropometric data and baseline lung function of the subjects are presented in Table 1. Of 94 preschool children, 92 children (98\%; 52 boys, mean age $4.2 \pm 1.1$ years) performed technically acceptable IOS and 75 (80\%, 42 boys, mean age $4.4 \pm 1.0$ years) performed technically acceptable spirometry; of the latter, three children completed baseline spirometry, but failed to perform spirometry at the last step.

\section{Comparison of $\mathrm{EOT}^{+}$and $\mathrm{EOT}^{\llcorner}$children}

Of the 72 children who successfully completed $\mathrm{FEV}_{1}, 51$ (70.8\%, mean age $4.4 \pm 1.1$ years) had a positive EOT $\left(\mathrm{EOT}^{+}\right)$ and $21(29.2 \%$, mean age $4.7 \pm 1.0$ years $)$ had a negative EOT
$\left(\mathrm{EOT}^{-}\right)$. There were no differences in age and gender between groups. The percent change, $\mathrm{z}$ score, and DRS of FEV ${ }_{1}$ were statistically different between groups, but the IOS test showed no significant difference except for DRS result (Table 2). Both

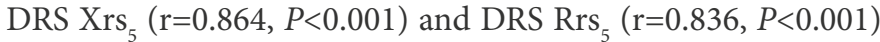

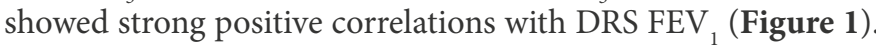
Moreover, DRS of $\mathrm{Rrs}_{5}$ and $\mathrm{Xrs}_{5}$ were strongly correlated with each other $(\mathrm{r}=0.911, P<0.001)$.

Table 1. Demographic characteristics and baseline lung function

\begin{tabular}{|c|c|}
\hline & $N=94$ \\
\hline Age, years $(95 \% \mathrm{CI})$ & $4.2(3.9,4.4)^{\star}$ \\
\hline Gender, boy/girl & $54 / 40$ \\
\hline Height, cm (95\% CI) & $107.4(105.7,109.1)^{*}$ \\
\hline Parental asthma, n (\%) & $7(7)$ \\
\hline Atopic dermatitis, $\mathrm{n}(\%)$ & $19(20)$ \\
\hline Allergic rhinitis, $n$ (\%) & $38(40)$ \\
\hline Secondary smoking (\%) & $51(54)$ \\
\hline $\begin{array}{l}\text { Impulse oscillometry }(\mathrm{n}=92) \\
\mathrm{Xrs}_{5} \text {, actual, } \mathrm{kPa} / \mathrm{L} / \mathrm{sec}(95 \% \mathrm{CI}) \\
\mathrm{Z} \text { score } \\
\mathrm{Rrs}_{5} \text {, actual, } \mathrm{kPa} / \mathrm{L} / \mathrm{sec}(95 \% \mathrm{CI}) \\
\mathrm{Z} \text { score }\end{array}$ & $\begin{array}{c}-0.44(-0.41,-0.47) \\
-0.86(-0.77,-0.96) \\
1.14(1.09,1.19) \\
-1.39(-1.09,-1.69)\end{array}$ \\
\hline $\begin{array}{l}\text { Spirometry }(\mathrm{n}=72) \\
\mathrm{FEV}_{\mathrm{l}}, \% \text { predicted }(95 \% \mathrm{CI}) \\
\mathrm{Z} \text { score, }(95 \% \mathrm{CI}) \\
\text { FEV }_{1} / \mathrm{FVC}, \%(95 \% \mathrm{CI})\end{array}$ & $\begin{array}{c}100.8(97.7,104.0) \\
0.37(0.07,0.67) \\
92.2(91.0,93.4)\end{array}$ \\
\hline
\end{tabular}

Table 2. Lung function test between $\mathrm{EOT}^{+}$and $\mathrm{EOT}^{-}$group in the 72 subjects

\begin{tabular}{|c|c|c|c|}
\hline & $\begin{array}{c}\mathrm{EOT}^{+} \text {group } \\
\mathbf{n}=51\end{array}$ & $\begin{array}{c}\text { EOT }^{-} \text {group } \\
n=21\end{array}$ & $P$ value \\
\hline \multicolumn{4}{|l|}{ Demographics } \\
\hline Age, years (SD) & $4.4(1.1)$ & $4.7(1.0)$ & 0.205 \\
\hline Gender, male (\%) & $31(60.8)$ & $9(42.9)$ & 0.164 \\
\hline Height, cm (SD) & $108.7(8.2)$ & $109.7(8.1)$ & 0.641 \\
\hline \multicolumn{4}{|l|}{$\mathrm{FEV}_{1}$} \\
\hline PC20 positive, $\mathrm{n}(\%)$ & $47(92.2)$ & $19(90.5)$ & 0.569 \\
\hline \%change $(95 \%, \mathrm{CI})$ & $39.2(35.1,43.2)$ & $30.9(26.1,35.6)$ & 0.019 \\
\hline Z score $(95 \%, C I)$ & $-3.82(-3.38,-4.26)$ & $-2.81(-2.23,-3.39)$ & 0.010 \\
\hline DRS, $(95 \%, \mathrm{CI})$ & $1.34(1.17,1.51)$ & $0.57(0.50,0.64)$ & $<0.001$ \\
\hline \multicolumn{4}{|l|}{${\mathrm{IOS} \_X r s_{5}}$} \\
\hline PC80 positive, n (\%) & $47(92.2)$ & $16(76.2)$ & 0.075 \\
\hline \%change $(95 \%, \mathrm{CI})$ & $176.8(154.9,198.8)$ & $159.2(119.0,199.4)$ & 0.404 \\
\hline Absolute change, $\mathrm{kPa} / \mathrm{L} / \mathrm{s}$ & $-0.72(0.81-0.63)$ & $-0.61(0.77-0.45)$ & 0.213 \\
\hline Z score & $-3.53(-3.14,-3.92)$ & $-3.07(-2.44,-3.71)$ & 0.212 \\
\hline DRS $(95 \%, C I)$ & $1.99(1.83,2.16)$ & $1.18(0.98,1.37)$ & $<0.001$ \\
\hline \multicolumn{4}{|l|}{ IOS_Rrs $_{5}$} \\
\hline PC40 positive, $\mathrm{n}(\%)$ & $34(66.7)$ & $16(76.2)$ & 0.425 \\
\hline$\%$ change $(95 \%, \mathrm{CI})$ & $53.6(45.1,62.0)$ & $53.2(42.4,63.9)$ & 0.958 \\
\hline Abs change, $\mathrm{kPa} / \mathrm{L} / \mathrm{s}$ & $0.57(0.49-0.64)$ & $0.56(0.46-0.67)$ & 0.975 \\
\hline Z score & $-5.24(-4.66 .-5.83)$ & $-5.12(-4.25,-5.99)$ & 0.809 \\
\hline DRS $(95 \%, C I)$ & $1.45(1.30,1.61)$ & $0.77(0.66,0.89)$ & $<0.001$ \\
\hline
\end{tabular}

EOT, end of test; IOS, impulse oscillation system; DRS, dose response slope;

$\mathrm{PC}_{20} \mathrm{FEV}_{1}, \mathrm{PC}_{80} \mathrm{Xrs}_{5}$ and $\mathrm{PC}_{40-} \mathrm{Rrs}_{5}$ positive mean that the rate of change in the last step from baseline decreased by $20 \%$ or more in FEV $\mathrm{Fh}_{1}$ when measuring by spirometry, decreased by $80 \%$ or more in reactance and increased by $40 \%$ or more in resistance when measuring by IOS.

$\%$ change means that the rate of change in the last step from baseline of $\mathrm{FEV}_{1}, \mathrm{Xrs}_{5}$ and $\mathrm{Rrs}_{5}$ during methacholine challenge test. 


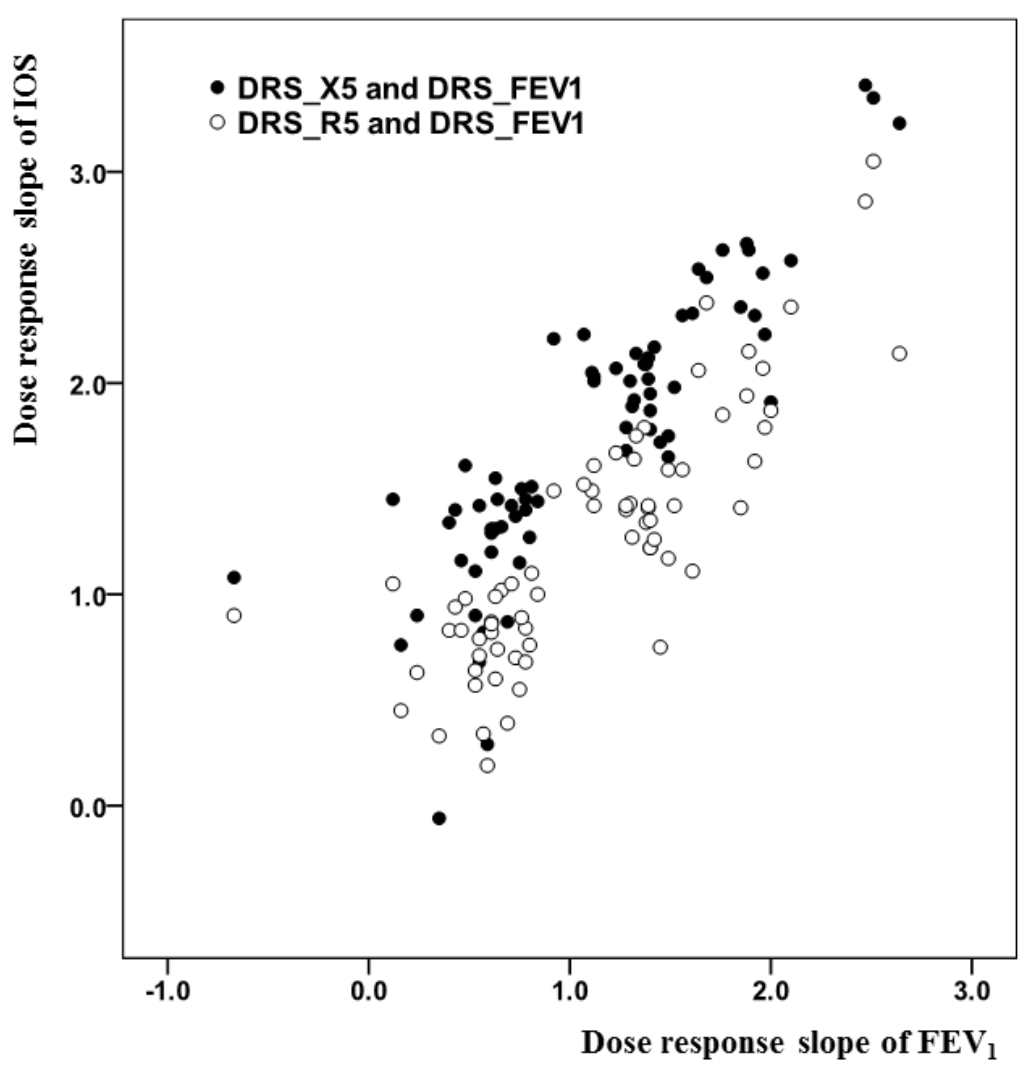

Figure 1. Correlation among the dose response slopes (DRS) of FEV , Rrs $_{5}$ and $\mathrm{Xrs}_{5}$. DRS_FEV 1 showed a stronger correlation with DRS_Xrs ${ }_{5}(\mathrm{r}=0.864, P<0.001)$ than with DRS_Rrs $(\mathrm{r}=0.836, P<0.001)$.

Comparison of lung parameters between $\mathrm{PC} \mathrm{w}^{+}, \mathrm{PCs}^{+}$, and $\mathrm{PCr}^{+}$

Among the $\mathrm{EOT}^{+}$subjects, there were 25 children in $\mathrm{PCw}^{+}, 10$ children in $\mathrm{PCs}^{+}, 9$ children in $\mathrm{PCr}^{+}$, and 26 children who showed wheeze and other conditions. The results of the lung function tests in the three groups for the reasons of discontinuation are shown in Table 3 . The change of the reactance value was the lowest in $\mathrm{PCr}^{+}$(median, 95.9, IQR; 73.4 to 132.4 ), followed by $\mathrm{PCw}^{+}$(median 151.3, IQR 78.2 to 203.8) and $\mathrm{PCs}^{+}$(median 232.7, IQR 207.0 to 273.7) $(P=0.001)$. The change of $\mathrm{Xrs}_{5}$ in all three EOT positive groups exceeded $80 \%$. There was no difference between the three groups with regard to the other pulmonary function tests.

Figure 2 shows the relative changes of $\mathrm{Xrs}_{5}$ (Figure 2A) and $\mathrm{Rrs}_{5}$ (Figure 2B) according to the degree of changes in oxygen saturation. The mean baseline $\mathrm{SpO}_{2}$ was $98.5 \pm 0.69 \%$ (range 98.4-98.7\%). There was a statistically significant difference between $\mathrm{Xrs}_{5}$ and $\mathrm{Rrs}_{5}$ among groups $(P<0.001)$. However, $\mathrm{Xrs}_{5}$ showed a higher correlation with changes in saturation $(\mathrm{r}=-0.578, P<0.001)$ than $\mathrm{Rrs}_{5}(\mathrm{r}=-0.426, P<0.001)$. The adjusted $\mathrm{R}$ squared of $\mathrm{Xrs}_{5}$ affecting $\mathrm{SpO}_{2}$ in regression coefficients was $0.34(P<0.001)$, whereas the adjusted $\mathrm{R}$ squared of $\operatorname{Rrs}_{5}$ was $0.18(P<0.298)$ (Table 4).

Table 3. Results of lung function tests categorized by the last step, grouping EOT $^{+}$

\begin{tabular}{|c|c|c|c|c|}
\hline & $\mathrm{PCw}^{+}$ & $\mathbf{P C s}^{+}$ & $\mathbf{P C r}^{+}$ & $P$ value \\
\hline \multicolumn{5}{|c|}{ Baseline lung function } \\
\hline $\mathrm{Xrs}_{5}, \mathrm{Z}$ score & $-0.77(-1.10$ to -0.59$)$ & $-0.76(-1.13$ to -0.58$)$ & $-0.45(-1.68$ to -0.20$)$ & 0.205 \\
\hline $\operatorname{Rrs}_{5}, Z$ score & $-1.54(-2.29$ to -0.02$)$ & $-0.90(-2.93$ to -0.54$)$ & $-1.63(-2.48$ to 0.33$)$ & 0.164 \\
\hline $\mathrm{FEV}_{1}, \mathrm{Z}$ score & $0.02(-1.25$ to 1.14$)$ & $0.00(-0.23$ to 1.37$)$ & $0.60(-0.73$ to 2.15$)$ & 0.641 \\
\hline $\mathrm{FEV}_{1} / \mathrm{FVC}$ & 93.0 (84.8 to 95.8$)$ & 96.1 (91.8 to 97.3$)$ & $93.2(83.7$ to 96.8$)$ & \\
\hline \multicolumn{5}{|c|}{$\mathrm{Xrs}_{5}$ last step lung function } \\
\hline \%change & $151.3(78.2$ to 203.8$)$ & $232.7(207.0 \text { to } 273.7)^{\star}$ & $95.9(73.4 \text { to } 132.4)^{\dagger}$ & 0.001 \\
\hline Z score & $-3.23(-3.67$ to -1.87$)$ & $-4.43(-5.11$ to -3.32$)$ & $-2.70(-3.66 \text { to }-1.14)^{\dagger}$ & 0.033 \\
\hline \multicolumn{5}{|c|}{$\mathrm{Rrs}_{5}$ last step lung function } \\
\hline \%change & $41.9(24.8$ to 70.1$)$ & 56.0 (34.8 to 79.6$)$ & 30.8 (20.7 to 49.1$)$ & 0.189 \\
\hline Z score & $-4.37(-6.30$ to -3.19$)$ & $-5.27(-8.51$ to -3.29$)$ & $-3.48(-5.89$ to -1.29$)$ & 0.229 \\
\hline \multicolumn{5}{|c|}{ FEV last step lung function } \\
\hline \%change & $-32.8(-44.1$ to -21.4$)$ & $-46.0(-48.8$ to -31.4$)$ & $-30.4(-53.5$ to -26.2$)$ & 0.520 \\
\hline Z score & $-3.79(-5.06$ to -2.15$)$ & $-3.82(-4.81$ to -2.57$)$ & $-3.45(-5.37$ to -2.19$)$ & 0.986 \\
\hline
\end{tabular}



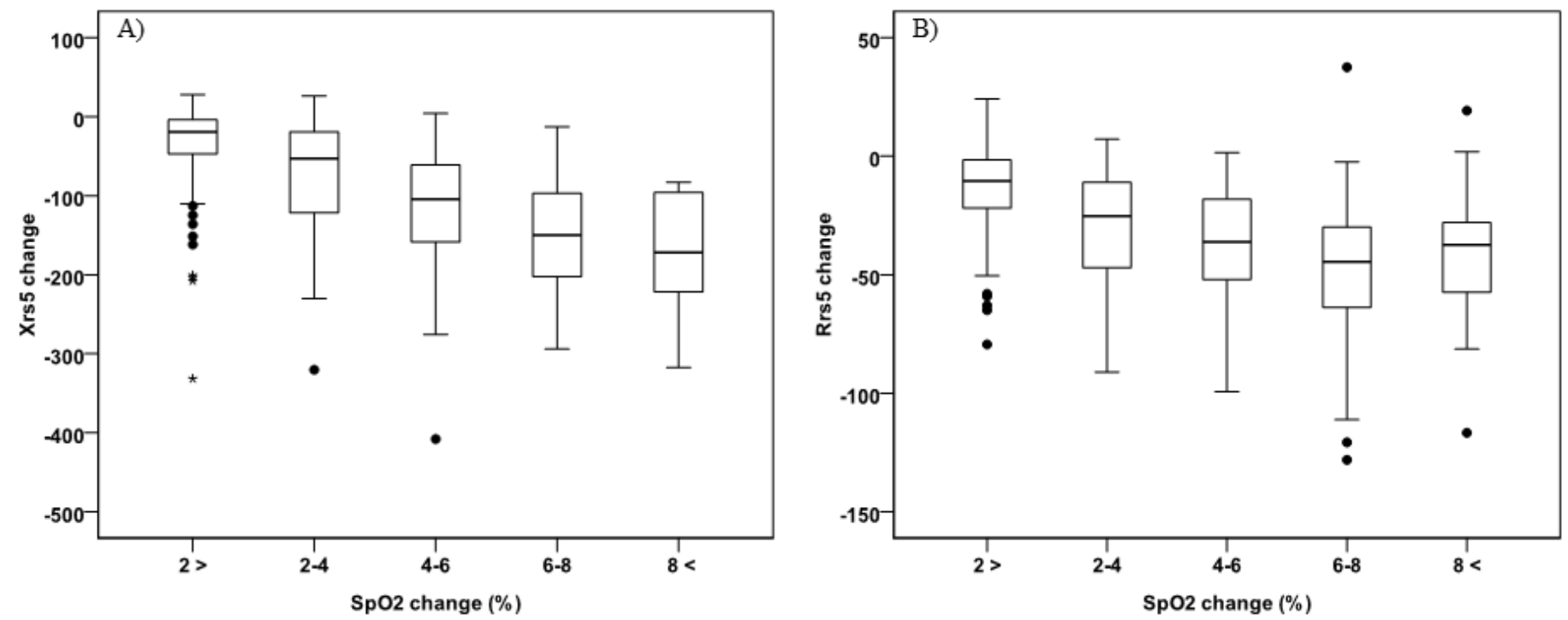

Figure 2. Relative changes in resistance and reactance at $5 \mathrm{~Hz}$ with regard to changes in $\mathrm{SpO}_{2}$. $\mathrm{Xrs}_{5}$ showed a higher inverse correlation with changes in saturation $(r=-0.578, P<0.001)$ than $\operatorname{Rrs}_{5}(r=-0.426, P<0.001)$.
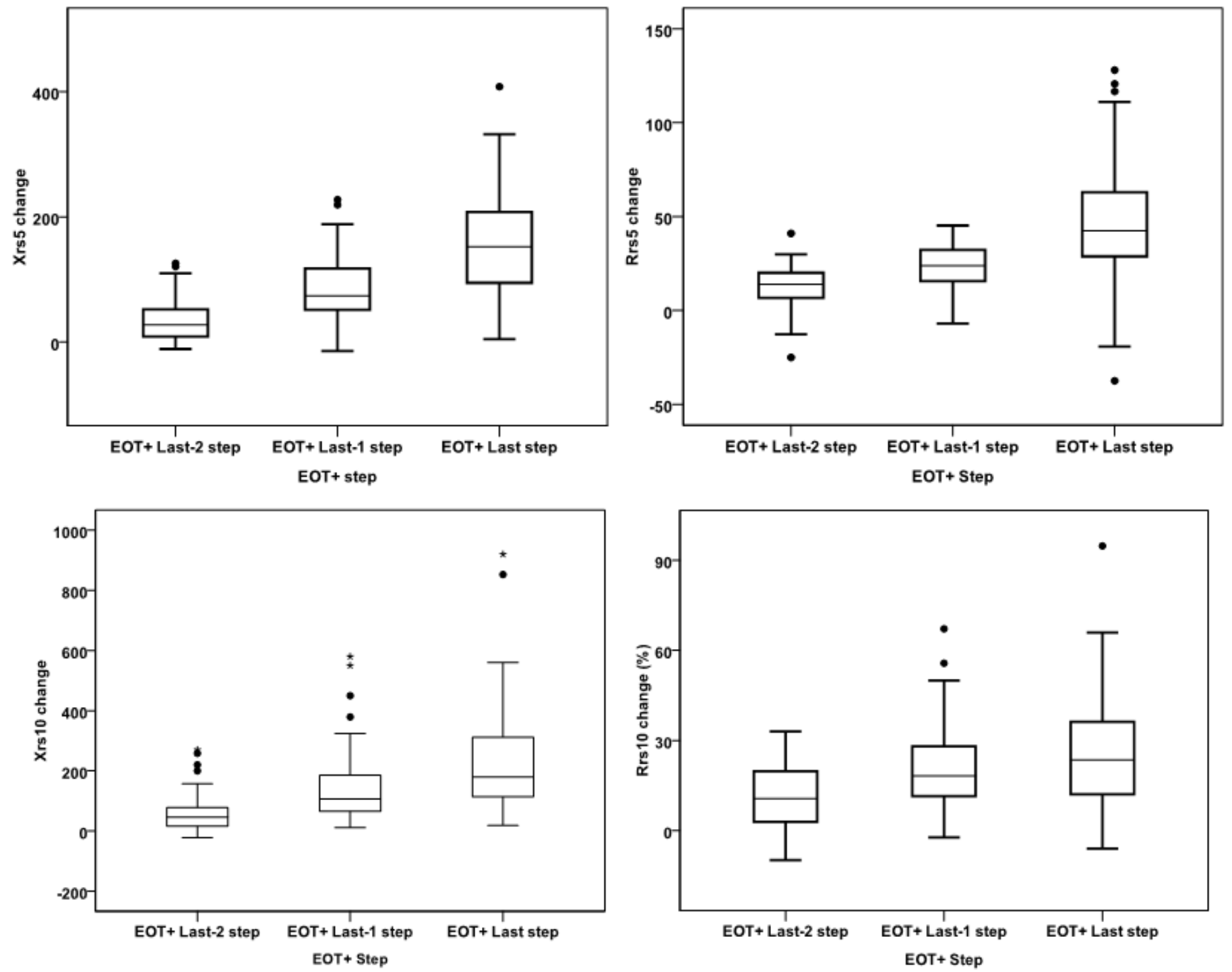

Figure 3. Mean percent changes in reactance and resistance at $5 \mathrm{~Hz}$ and $10 \mathrm{~Hz}$ at $\mathrm{EOT}^{+}$, one step prior to $\mathrm{EOT}^{+}$and two steps prior to $\mathrm{EOT}^{+}$in all subjects. At $\mathrm{EOT}^{+}$, all parameters changed significantly compared to the previous step $(P<0.001)$. 

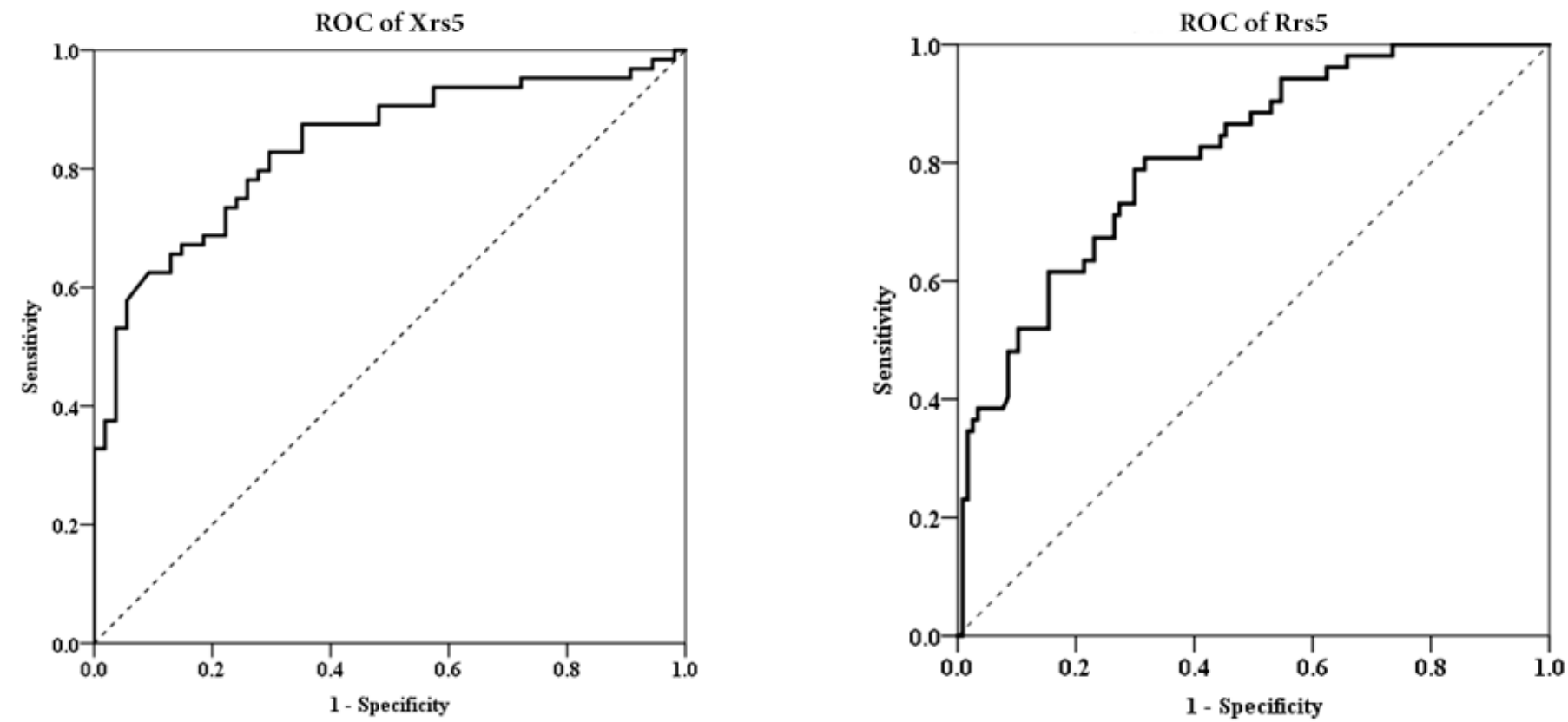

Figure 4. The ROC curves describing the relationship between the sensitivity and specificity in the percent change of $\mathrm{Xrs}_{5}$ and $\mathrm{Rrs}_{5}$ for the prediction of $\mathrm{PC}_{80}{ }_{2} \mathrm{Xrs}$ and $\mathrm{PC}_{40}$. The AUC of $\mathrm{Xrs}_{5}$ was larger than that of Rrs ${ }_{5}$.

\section{Changes in IOS parameters before EOT}

Since the parameters of IOS are susceptible to changes before the occurrence of airway obstruction, we assessed percent changes in lung function from baseline to Last-1 and Last-2 steps as well as the last step (Figure 3). All parameters demonstrated significant changes when compared with the previous step $(P<0.001)$. Using ROC curves, we determined the relationship between the sensitivity and specificity in the percent change of $\mathrm{Xrs}_{5}$ and $\mathrm{Rrs}_{5}$ for predicting of $\mathrm{PC}_{80} \mathrm{Xrs}_{5}$ and $\mathrm{PC}_{40} \mathrm{Rrs}_{5}$ (Figure 4). The AUC of $\mathrm{Xrs}_{5}(0.837,95 \% \mathrm{CI}$ 0.765-0.909) was larger than that for $\operatorname{Rrs}_{5}$ (0.812, 95\% CI 0.744-0.879). A forty-nine percent decrease in $\mathrm{Xrs}_{5}$ was the optimal point of sensitivity (62.5\%) and specificity (90.7\%) for predicting a $80 \%$ change of $\mathrm{Xrs}_{5}$ at the following step. The cutoff point of $\mathrm{PC}_{40} \mathrm{Rrs}_{5}$ was $19.1 \%$ with a lower sensitivity and specificity $(31.6 \%$ and $68.4 \%$, respectively) than those of reactance.

\section{Discussion}

In this study we measured the relative changes and $\mathrm{Z}$ scores of $\mathrm{Xrs}_{5}$ and $\mathrm{Rrs}_{5}$ when EOT was reached. We found that percent change of $\mathrm{FEV}_{1}$ in preschool children was similar to that observed in previous studies with the presence of wheezing. ${ }^{3,4,27}$ When the test was stopped due to respiratory symptoms, resistance did not exceed $40 \%$ and positive rate of $\mathrm{PC}_{40}-\mathrm{Rrs}_{5}$ was even higher in $\mathrm{EOT}^{-}$group than that in $\mathrm{EOT}^{+}$group. Therefore, a $40 \%$ change in $\operatorname{Rrs}_{5}$ may not be an appropriate parameter in bronchial challenge testing. The percent changes and $\mathrm{Z}$ scores of $\mathrm{Xrs}_{5}$ better represent changes in saturation than percent changes and $\mathrm{Z}$ scores of $\mathrm{Rrs}_{5}$. Although $\mathrm{FEV}_{1}$ and $\mathrm{Xrs}_{5}$ reflect different pathophysiologic changes in the lungs, $\mathrm{Xrs}_{5}$ showed good agreement with the decline in $\mathrm{FEV}_{1} \cdot{ }^{28}$ Because it is difficult to process the 10 steps of bronchoprovocation tests with doubling doses in preschool children, we suggest beginning the test by quadrupling doses and switching to doubling doses when $51.4 \%$ of $\mathrm{Xrs}_{5}$ is reached.

In children with $\mathrm{EOT}^{+}$, they show higher changes than the reference values in most cases. ${ }^{21,24,25}$ In addition, pulmonary function test was positive even when EOT was negative in many cases. With regard to resistance, positive rate of $\mathrm{PC}_{40} \mathrm{Rrs}_{5}$ was even higher in the $\mathrm{EOT}^{-}$group than that in the $\mathrm{EOT}^{+}$group. This suggests that even if the respiratory symptoms are absent, oxygen saturation is normal, or wheezing is not auscultated, the patient may already have bronchoconstriction and thus be in danger of developing respiratory difficulty in some cases. Therefore, these clinical parameters were not able to detect the pulmonary function changes at the early stage, and if these are used as a standard endpoint for the bronchial challenging test, the diagnosis of asthma may not be made accurately and be at risk sometimes.

Comparing $\mathrm{Xrs}_{5}$ and $\mathrm{Rrs}_{5}$ in IOS, the changes of $\mathrm{Xrs}_{5}$ in all three EOT positive groups exceeded $80 \%$ compared to the results reported in previous studies and were lowest in $\mathrm{PCr}^{+}$, followed by $\mathrm{PCw}^{+}$and $\mathrm{PCs}^{+}$. On the other hand, $\mathrm{Rrs}_{5}$ did not show greater than a $40 \%$ change even when the child had to stop the test due to respiratory symptoms. This suggests that $\mathrm{PC}_{40} \_\mathrm{Rrs}_{5}$ may not be a suitable value in preschoolers during challenge test. As a sensitive indicator of airway obstruction, $\mathrm{Xrs}_{5}$ is more useful than $\mathrm{Rrs}_{5}$, a finding corresponding well with previous studies. ${ }^{24}$ The parameters of IOS and spirometry reflect different properties of the respiratory system. ${ }^{2}$ However, changes in IOS parameters are well correlated with those in $\mathrm{FEV}_{1}$ in many studies. ${ }^{7,14,23}$ As shown in our previous studies, we investigated which IOS parameter is more correlated with BHR and found that reactance better reflects BHR than resistance. We do not have clear explanation for this finding. Further research is warranted to describe the significant physiological correlation of reactance with BHR. 
Since the respiratory symptoms and wheezing were not comparable with IOS parameters numerically during the examination, we compared the changes in oxygen saturation with parameters and reactance showed a more significant change with the saturation. Consequently, in preschoolers, reactance, rather than resistance, reflects bronchial hyperresponsiveness in methacholine challenge test. As we previously mentioned, the clinical parameters may lead to a dangerous situation in preschooler because most of cases have already exceeded the reference value when the test was completed and we found the reactance was a better parameter for determining the bronchial hyperresponsiveness. Therefore, we determined the optimal reactance value for examining carefully before proceeding the test by comparing the last step with the previous steps, and found that a $49 \%$ decrease in $\mathrm{Xrs}_{5}$ indicated an $80 \%$ change in reactance at the following step. Thus, if the reactance decreases to near $49 \%$ in preschoolers during the methacholine test, we recommend lowering the concentration at the next step.

The appropriate increases in concentration during methacholine challenge testing have not been determined. Some recent studies reported that preschool children successfully completed methacholine challenge testing when concentrations were tripled. ${ }^{29,30}$ However, these studies are limited in that they included a small number of subjects and that the initial start-up concentration was relatively high, and the test time was short. In contrast, our study using methacholine in four fold increments had a lower success rate of spirometry, but the IOS success rate was even higher up to $98 \%$. Therefore, we suggest that in the case of young preschoolers, the methacholine test using spirometry can be performed by raising the starting concentration and increasing the concentration by three or four times. It may also be useful to perform methacholine test using IOS due to the notion that IOS requires minimal patient cooperation. The risk of severe bronchoconstriction can be minimized by lowering the concentration when a certain change is observed in previous results. However, further research is needed to determine changes in lung function when apply doubling doses. Another limitation was the difficulty of defining EOT $^{-}$due to lack of a healthy control group.

In the methacholine challenge test using IOS, which can be done more easily in preschooler than spirometry, reactance better reflects bronchial hyperresponsiveness than resistance. Therefore, we suggest switching to doubling doses when reactance reaches a certain level in order to minimize the risk of severe bronchoconstriction and increase the success rate.

\section{Acknowledgements}

No author has a financial conflict of interest with regard to the material presented in this paper.

\section{References}

1. Cockcroft DW. Methacholine challenge methods. Chest. 2008;134:678-80.

2. Beydon N, Davis SD, Lombardi E, Allen JL, Arets HG, Aurora P, et al. An official American Thoracic Society/European Respiratory Society statement: pulmonary function testing in preschool children. Am J Respir Crit Care Med. 2007;175:1304-45

3. Noviski N, Cohen L, Springer C, Bar-Yishay E, Avital A, Godfrey S. Bronchial provocation determined by breath sounds compared with lung function. Arch Dis Child. 1991;66:952-5.
4. Springer C, Godfrey S, Picard E, Uwyyed K, Rotschild M, Hananya S, et al. Efficacy and safety of methacholine bronchial challenge performed by auscultation in young asthmatic children. Am J Respir Crit Care Med. 2000;162(3 Pt 1):857-60.

5. Yong SC, Smith CM, Wach R, Kurian M, Primhak RA. Methacholine challenge in preschool children: methacholine-induced wheeze versus transcutaneous oximetry. Eur Respir J. 1999;14:1175-8.

6. Wilson NM, Bridge P, Phagoo SB, Silverman M. The measurement of methacholine responsiveness in 5 year old children: three methods compared. Eur Respir J. 1995;8:364-70.

7. Bouaziz N, Beyaert C, Gauthier R, Monin P, Peslin R, Marchal F. Respiratory system reactance as an indicator of the intrathoracic airway response to methacholine in children. Pediatr Pulmonol. 1996;22:7-13.

8. Jee HM, Kwak JH, Jung da W, Han MY. Useful parameters of bronchial hyperresponsiveness measured with an impulse oscillation technique in preschool children. The Journal of asthma : official journal of the Association for the Care of Asthma. 2010;47(3):227-32.

9. Kivastik J, Gibson AM, Primhak RA. Methacholine challenge in pre-school children--which outcome measure? Respir Med. 2007;101:2555-60.

10. Harrison J, Gibson AM, Johnson K, Singh G, Skoric B, Ranganathan S. Lung function in preschool children with a history of wheezing measured by forced oscillation and plethysmographic specific airway resistance. Pediatr Pulmonol. 2010;45:1049-56.

11. Klug B, Bisgaard H. Measurement of lung function in awake 2-4-year-old asthmatic children during methacholine challenge and acute asthma: a comparison of the impulse oscillation technique, the interrupter technique, and transcutaneous measurement of oxygen versus whole-body plethysmography. Pediatr Pulmonol. 1996;21:290-300.

12. Gangell CL, Hall GL, Stick SM, Sly PD, Arest CF. Lung function testing in preschool-aged children with cystic fibrosis in the clinical setting. Pediatr Pulmonol. 2010;45:419-33.

13. Komarow HD, Myles IA, Uzzaman A, Metcalfe DD. Impulse oscillometry in the evaluation of diseases of the airways in children. Ann Allergy Asthma Immunol. 2011;106:191-9.

14. Schulze J, Smith HJ, Fuchs J, Herrmann E, Dressler M, Rose MA, et al. Methacholine challenge in young children as evaluated by spirometry and impulse oscillometry. Respir Med. 2012;106:627-34.

15. Bailly C, Crenesse D, Albertini M. Evaluation of impulse oscillometry during bronchial challenge testing in children. Pediatr Pulmonol. 2011;46: 1209-14.

16. Chung KF, Wenzel SE, Brozek JL, Bush A, Castro M, Sterk PJ, et al. International ERS/ATS guidelines on definition, evaluation and treatment of severe asthma. Eur Respir J. 2014;43:343-73.

17. Shin YH, Baek JH, Yoon JW, Jee HM, Yum HY, Choi SH, et al. Comparison of Reference Values and Short-Term Variability for Oscillatory and Spirometric Lung Function in Healthy Korean Preschool Children. Pediatr Allergy Immunol Pulmonol. 2013;26:25-31.

18. Purohit A, Bohadana A, Kopferschmitt-Kubler MC, Mahr L, Linder J, Pauli G. Lung auscultation in airway challenge testing. Respir Med. 1997;91: 151-7.

19. Renwick DS, Connolly MJ. Factors affecting oxygen saturation during methacholine challenge in a mixed population. Respir Med. 1996;90:473-7.

20. Jayet PY, Schindler C, Kunzli N, Zellweger JP, Brandli O, Perruchoud AP, et al. Reference values for methacholine reactivity (SAPALDIA study). Respir Res. 2005;6:131.

21. Vilozni D, Livnat G, Dabbah H, Elias N, Hakim F, Bentur L. The potential use of spirometry during methacholine challenge test in young children with respiratory symptoms. Pediatr Pulmonol. 2009;44:720-7.

22. Bohadana AB, Peslin R, Megherbi SE, Teculescu D, Sauleau EA, Wild P, et al. Dose-response slope of forced oscillation and forced expiratory parameters in bronchial challenge testing. Eur Respir J. 1999;13:295-300.

23. Yoon JW, Shin YH, Jee HM, Chang SJ, Baek JH, Choi SH, et al. Useful marker of oscillatory lung function in methacholine challenge test -comparison of reactance and resistance with dose-response slope. Pediatr Pulmonol. 2014;49:521-8.

24. Kim HY, Shin YH, Jung DW, Jee HM, Park HW, Han MY. Resistance and reactance in oscillation lung function reflect basal lung function and bronchial hyperresponsiveness respectively. Respirology. 2009;14:1035-41.

25. Broeders ME, Molema J, Hop WC, Folgering HT. Bronchial challenge, assessed with forced expiratory manoeuvres and airway impedance. Respir Med. 2005;99:1046-52.

26. Hellinckx J, De Boeck K, Bande-Knops J, van der Poel M, Demedts M. Bronchodilator response in 3-6.5 years old healthy and stable asthmatic children. Eur Respir J. 1998;12:438-43. 


\section{APJAI}

27. Bentur L, Beck R, Elias N, Barak A, Efrati O, Yahav Y, et al. Methacholine bronchial provocation measured by spirometry versus wheeze detection in preschool children. BMC Pediatr. 2005;5:19.

28. Duiverman EJ, Neijens HJ, Van der Snee-van Smaalen M, Kerrebijn KF. Comparison of forced oscillometry and forced expirations for measuring dose-related responses to inhaled methacholine in asthmatic children. Bull Eur Physiopathol Respir. 1986;22:433-6.
29. Kivastik J, Gibson AM, Primhak RA. Feasibility of shortened methacholine challenge in preschool children. Pediatr Pulmonol. 2006;41:146-50.

30. Vilozni D, Hakim F, Adler A, Livnat G, Bar-Yishay E, Bentur L. Reduced vital capacity after methacholine challenge in early childhood--is it due to trapped air or loss of motivation. Respir Med. 2009;103:109-16. 